\title{
Children, play, and computers in pre-school education
}

\section{Lydia Plowman and Christine Stephen}

Dr Lydia Plowman has particular interests in ICT and children's learning and Dr Christine Stephen is a specialist in early years education and the transition to primary school. Address for correspondence: Institute of Education, University of Stirling, Stirling FK9 4LA, Scotland. Email: lydia.plowman@stirac.uk or christine.stephen@stirac.uk

\begin{abstract}
The paper reports a study designed to inform the development of an information and communication technology strategy for the pre-school years of education. The main methods of collecting evidence were observations at seven pre-school settings and interviews with at least two practitioners and a number of children at each site. Practitioners generally referred to children "playing with the computer". We describe some of the problems to be found in the emphasis on free play in nurseries and play groups when this means children are using computers as complete novices. There were few examples of peer support; adults rarely intervened or offered guidance and the most common form of intervention was reactive supervision. Interaction with a computer was therefore a limited experience for most children, but we provide examples of guided interaction that suggest a way forward for professional development.
\end{abstract}

\section{Introduction}

Pre-school education is a particularly interesting area for investigating the use of computers. Pre-school environments offer opportunities to observe the relationship between formal and informal learning, the balance between learner-centred and adultdirected activities, and the use of computers by children who are unable to follow textbased instructions. The study described here took place in Scotland, where almost all 4-year-olds (99\%) and 83\% of 3-year-olds are in part-time pre-school education, funded by the government and provided by the public, private, or voluntary sectors (Scottish Executive, 2003). Children start formal school education at the age of five in Scotland so "pre-school education" is defined as provision across these three sectors for children aged between 3 and 5 in the two years before they begin school.

The interest in information and communication technology (ICT) in pre-school settings comes at a time when there is widespread (although not unequivocal) support for the value of computers in educational settings and a political commitment to their intro-

(C) British Educational Communications and Technology Agency, 2005.

Published by Blackwell Publishing, 9600 Garsington Road, Oxford, OX4 2DQ, UK and 350 Main Street, Malden, MA 02148, USA. 
duction. The starting age for schooling across European countries ranges from four to seven (Sharp, 2002) and there appears to be a desire to prepare children of all ages for what is seen as an increasingly complex and technological world. In the UK, computers are seen by the government and others as having the potential to improve the quality and standards of pupils' education in addition to supporting teachers in their everyday classroom roles.

Governments across Europe are introducing computers at progressively earlier stages of education but policies that have been developed for schools are not necessarily transferable to pre-school settings. This is because, in the UK, there are cultural differences between learning in the pre-school sector and learning in schools to be taken into account, including:

- the curriculum and assessment are less prescriptive for pre-school settings and the role of computers in driving up standards is not yet explicitly stated in pre-school policy documents;

- pre-school practitioners have a diverse range of qualifications and experience and settings sometimes have very few staff;

- pre-school settings do not generally have a high level of ICT resources and few practitioners have been involved in ICT training available to school teachers; and

- there are different norms of professional practice with reference to formal, adultdirected teaching and an emphasis on learning through play.

The Scottish Executive (the devolved government for Scotland) initiated a review of ICT in pre-school settings to encompass (1) a framework showing how ICT can enhance and support young children's development and learning and (2) a strategy to inform the planning and delivery of initial training for practitioners and their further professional development. Learning and Teaching Scotland, a government-funded agency that develops the curriculum and the role of ICT in promoting learning, was tasked with meeting these objectives and commissioned us to review the literature on ICT in preschool settings. This review (Plowman \& Stephen, 2003; Stephen \& Plowman, 2003a) revealed that there was insufficient practice-based evidence on which to build decision making so we were subsequently commissioned to undertake the research described here. The aim of this research was to use a case study approach to describe the use of ICT in seven pre-school settings in terms of what was available and how it was used by adults and children.

At the time of this study, government-funded education in Scotland was delivered in accordance with the Curriculum Framework for Children 3 to 5 (SCCC, 1999). This document does not make a detailed reference to ICT, although within the curriculum area "Knowledge and understanding of the world" it states:

The children's environment is one in which technology is important in their everyday lives. As children use blocks, put on a warm jumper, look through a magnifying glass, clamber on to a climbing frame, use a computer or travel by train, they become aware of the everyday uses of technology in the home, in transport, in communication and in leisure. (p. 23) 
Play is the dominant medium for learning in Scottish pre-school education and there is a consensus that pedagogy and practice should be child-centred, an approach manifested by children choosing what to do during extended periods of free play. Although this approach is supplemented by planned, adult-led small group activities in most areas of the pre-school curriculum, this was not the case for learning with technologies. This paper examines computer use as a play activity and what this means for children's interactions with each other, with the computer, and with adults.

\section{Defining ICT}

For the purposes of our study we used a broad definition of ICT that encompassed a variety of audio-visual resources, "smart" toys, and everyday technologies, such as remote control devices, photocopiers, telephones, fax machines, televisions, and computers. We also included toys that simulate appliances such as mobile phones, laptops, cash registers, microwave ovens, and barcode readers as well as computers and their peripheral devices. Practitioners did not have such a broad view of ICT, defining it more narrowly as computers and printers, even at sites where they used items such as digital cameras and tape recorders. As use of these technologies was very limited (see later section on ICT in the pre-school settings), this account focuses on computers, although the study was originally prompted by the need to review the use of ICT.

\section{Research on computers and early years education}

Our recent survey of the literature (op. cit.) reviewed the international research evidence on the ways in which ICT is used in pre-school settings and pointed to the paucity of good evidence-based writing on the subject. The emphasis has been on computers rather than on the broader view of ICT outlined above and many reports and web sites make claims for the benefits to be derived from children using computers. Others have questioned the relationship between computers and the cognitive, social, and developmental needs of young children, claiming that computers are detrimental to health and learning (Cordes \& Miller, 2000; Healy, 1998). The evidence base for much of this writing is weak and proponents of either position tend to rely on assertion rather than empirical study. Although there are exceptions, such as a report on the use of a computer in one nursery (Brooker \& Siraj-Blatchford, 2002) and the report of the KidSmart programme, which is on a larger scale but uses equipment and software provided by IBM (Siraj-Blatchford \& Siraj-Blatchford, 2001), we know little about the ways in which children react to and interact with the technology available in the playroom. Li and Atkins (2004) have used various tests to assess the association between early computer experience and cognitive and motor development but this was based in children's homes.

There is a consensus between policy makers, practitioners, academics, and parents on the relationship between play and learning and, increasingly, on the benefits of introducing children to ICT at an early age but there is little evidence-based guidance available for its use in pre-school education (but see Siraj-Blatchford \& Siraj-Blatchford, 2003). 


\section{Design of the study}

The seven case study settings were selected to provide a balance across the different sectors: three were local authority nursery schools, two were private sector nurseries, and two were voluntary sector playgroups. They were located in several local authorities in central Scotland in both urban and rural settings. One of the nursery schools was selected specifically because it was networked as a result of an authority-wide initiative and had access to the Internet. The other six settings were selected not because of any specific technology use or provision but rather as examples of pre-school provision that were reported to be of good overall quality and offered government-funded places.

Data collection consisted of interviews with at least one practitioner and the manager at each of the seven sites, observations, and brief conversations with children. Interviews with practitioners and managers took place immediately before or after the observation sessions and were audio-recorded for later transcription. Conversations with children were of necessity informal, brief, and opportunistic. Six questions guided our data collection:

1. What ICT resources are available in the playroom and what support is offered to staff using the resources?

2. To what extent do children choose to use the ICT resources available and how do they interact with them?

3. To what extent are references to ICT resources incorporated into (i) plans for free play or adult-led activities in the playroom and (ii) assessments of children's development and learning?

4. What ICT resources do practitioners draw on for the production of materials for the playroom, for access to information, and for administration?

5. What advantages or disadvantages do practitioners consider that ICT offers for their practice and for children's learning?

6. To what extent are practitioners aware of children's engagement with ICT at home and how does this influence their practice?

Each setting was observed during two half-day sessions. The observation record noted the nature and duration of each episode with different types of ICT, the involvement of adults or other children, and the level of children's engagement. Episodes of use could be as short as 30 seconds or, rarely, as sustained as 30 minutes and could involve a child alone, a fluctuating group of children, some adult-child interaction, or a combination of these. The observation record also included the number of adults and children present in the setting and the ways in which practitioners were deployed.

A case study approach was adopted to allow a rich description of the experience of ICT use in particular contexts. Whilst the modest scale of the study does not allow broad generalisations, the cross-section of sites visited enabled us to reach conclusions of value to the policy development process. Analysis involved producing a profile of each site and then producing an overview summarising findings common across settings and factors found to be influential regardless of specific contexts. The full report (Stephen \& 
Plowman, 2003b) discusses all of the research questions above; this paper focuses on evidence relating to the first two questions but draws on data for the others.

\section{ICT in the pre-school settings}

The presence of a computer was a common feature of all seven settings, although this had not been a criterion for selection in the study. At six of the sites the computer was placed in the main activity room along with a range of other resources such as a water tray, nature table, or book display. At one of the private nurseries the computer was located in an area adjoining the main room and there were plans to equip a small computer suite. Furniture ranged from purpose-built desks and benches to tables and chairs that were unsuitable, either ergonomically or because they were not designed to encourage collaboration. All settings had access to television, video, and audio equipment and practitioners at three sites used digital cameras.

As desktop computers were the most ubiquitous form of ICT in the settings visited (and often the only form observed in use), the remainder of this paper focuses on the children's engagement with computers. Children were offered daily opportunities to use a computer during free-play periods at all but one of the settings. Only one site organised scheduled teacher-directed time at a computer in addition to free-play opportunities but this was infrequent.

Both PCs and Macs were used, ranging in age from brand new to many years old. An old Mac at a local authority site was unusable because there was no compatible software but the age of equipment was not referred to as a problem elsewhere. At least one computer had been supplied by the local authority to each of the public sector nursery schools while additional machines there and in other settings were the result of fundraising, donations or specific grants. Although most settings had access to the Internet from the office, it was only possible to access it from the playroom in two nurseries and we did not observe use of the Internet by children. Practitioners talked more about accessing the Internet at home than at the nursery and there was little reported use of web sites as a resource.

\section{Playing with the computer}

Children's interactions with the computer were frequently referred to, by adults and children, as "playing with the computer" in the same way as they would talk about playing with the bricks or the model animals. This is not surprising inasmuch as the dominant ethos of pre-school environments is that children learn through play and much of the software used a games format. Children's encounters with books, crayons, and paints were not referred to as play activities, probably because their role in the curriculum was easily identified and practitioners were used to recording children's development in the areas of reading, writing, and drawing.

The culture of pre-school practice values a child-centred approach. This perspective is reflected in the emphasis on children choosing when to play with the computer and which software to use, as summed up by one of the practitioners: 
If they want to access it then they access it. If they don't, then we leave them.

Children's freedom to choose resulted in highly varied patterns of engagement. Sian, for instance, used Milly's Math House for 15 minutes without speaking to another adult or child or looking away from the screen. Others changed CD-ROMs or tried different games almost at random, rarely staying with one activity for more than a minute. On several occasions we observed children leave after unsuccessful attempts to complete a task or game. Sometimes the computer was not used at all during the observed free-play session and children ignored it, preferring to play outside, use construction equipment, make pictures, or play in the house corner. There is a paradox when our observations showed that boredom, frustration, and disengagement were common responses but features associated with play (such as fun, pleasure, spontaneity, and enjoyment) were rarely observable in activities referred to as playing with the computer.

\section{Interactions with each other}

Children's interactions with each other at the computer generally fell into three categories:

- negotiating access and taking turns;

- managing operations, such as deciding where to click; and

- sharing enjoyment of the action depicted on the screen.

Negotiating access and managing operations dominated children's play. At most settings there were rules limiting the number of children at the computer, as there were for other activities, and two children were generally allowed to work together with another place sometimes allocated for a child waiting for a turn. Children were observed keeping the computer under surveillance while busy elsewhere so that they could move quickly to the machine when it was free. Alternatively, they would demand to have a turn, then wait alongside until the current user left. At some sites an egg timer was used to measure the duration of a turn, in which case a typical period of engagement with the computer was about 5 minutes.

Children sometimes worked together, helping each other to interpret error messages or discussing which option to select, but we did not observe any child offering others explicit help that would enable them to learn what to do when they encountered such difficulties again. If the more competent child said anything, it tended to be an instruction such as "do this" or "press that" without an explanation. More typically, the child experiencing difficulties deferred to another who could complete the exercise at the risk of the expert child using the intervention as an opportunity to take over the game.

There were some occasions when play was an appropriate term to describe interactions: when playing together, and sometimes when alone, children exclaimed at their success and called for others to look or laughed at some animation or goal achieved ("Look at that!"; "I love dinosaurs dancing"; cries of "yessss" and "hooray"). Some children deliberately completed a task incorrectly if they enjoyed the response of the screen-based characters telling them to try again but these more playful interactions were relatively unusual. 


\section{Adult involvement in computer play}

In all settings practitioners had responsibility for a number of activities or a particular area of the room. This meant that supervision of children playing at the computer was limited, opportunistic, and shared with other supervisory duties. Children sometimes asked for help but otherwise adults became involved with computer play only if they noticed a need for intervention. The location of the computer was critical: supervision is almost impossible if the computer is kept in a corner but finding a suitable position is difficult when it cannot be near sand and water or in an area with high levels of traffic. A casual glance may be adequate for assessing the state of play in the house corner, but it is not possible to establish interactions at a computer by this means. Most supervision therefore consisted of checking that children were taking turns and ensuring that they were not doing anything that could incur damage rather than providing tailored assistance.

Based on our observations and descriptions of practice, we identified three broad categories of adult involvement in computer play: reactive supervision, guided interaction, and a hybrid approach that combined elements of both.

\section{Reactive supervision}

Reactive supervision was the most common form of adult guidance. The approach operated by default rather than constituting a pedagogical strategy, although it was associated with children choosing for themselves when or if they would use the computer and what they would do. It was most commonly manifested as keeping a check on turn-taking and length of time at the computer. At most sites, the free-play approach entailed children going to the computer when they could see it was free and if there did not appear to be anything more engaging on offer, although some children actively sought it out. The child would then typically choose from a range of five to ten software titles and start playing if they knew how to load the CD-ROM and open the program.

Children rarely requested help when interacting with the computer other than to request turn-taking interventions. Problems were commonplace, so it was difficult for adults to identify times when children needed help and if children encountered difficulties they tended to give up and walk away. Sometimes they were oblivious to a problem and would continue clicking at random; it was only at the point when this resulted in the screen freezing that they might seek help. This meant that, for much of the time, children's interactions with computers could not really be described as contributing directly to play or learning, other than the social aspects of negotiating access. When asked how they identified what children were learning, adults acknowledged that it was difficult to pinpoint (as is also true for older children) unless staff engaged the children in dialogue:

You can never be sure what they are learning. You are assuming that if you ask them something about what they have been doing they will be able to explain-sometimes they just watch. You have to ask and see what they have learned.

These conversations about learning at the computer were unusual. 


\section{Guided interaction}

Guided interaction has been used to describe the ways in which the interface can offer guidance (Plowman, 1996a) or the ways in which a learned sense of narrative can guide navigation, comprehension, and accessibility (Plowman, 1996b) for software used in schools. We have expanded the concept to include the role of human help in guiding interaction, focussing on the ways in which a practitioner sits with one or more children and actively assists them to interact with the computer. Based on our observations, we identified a number of ways of providing guided interaction:

- explaining how to use the software;

- placing a hand over a child's hand as he or she moves the cursor or clicks on an icon;

- suggesting alternative actions;

- demonstrating how to use a tool such as the eraser;

- moving children to an appropriate level of difficulty;

- offering remedial help when errors occur;

- providing positive feedback on a task completed;

- sharing pleasure in features such as animation; and

- intervening in turn-taking and ensuring that individual children do not dominate.

A real-life scenario that demonstrates some of the features of guided interaction in practice is provided below.

Margaret sat beside Steven at the computer. He was interested in the Pingu CD-ROM but selected quit by mistake. She helped him get back to Snowball Alley and spoke encouragingly to him as he used the mouse to drag objects into position. Margaret asked Steven to count the number of snowmen and to repeat the numbers. He appeared to be totally absorbed most of the time but occasionally pointed to the screen or turned towards Margaret, looking very pleased. Margaret decided that John should join Steven. She changed the game to one suitable for two players and showed them how to drag and drop. She sat on a small chair alongside the boys in a position where she could see the screen and the children. When another boy approached, Margaret prompted the others to include him in the turn-taking and showed him how to drag and drop.

About 20 minutes later, Sarah went to the computer when she realised that it was free. Margaret asked her to sit properly on the bench then sat next to her and told her how to use the mouse. Sarah had picked up a game for two players mid-way through and Margaret guided her to a different one, placing her hand over the child's to guide her. Once she had explained the game, Margaret started the timer. Sarah played the game excitedly then began to change games (apparently at random) when Margaret left to attend to a child elsewhere.

Guided interaction is time-consuming and resource intensive because it requires interaction on a one-to-one or small group basis. It also requires staff who feel comfortable 
with this level of involvement but, other than in isolated cases, we found very low levels of confidence and competence with ICT.

\section{Hybrid approach}

One of the private nurseries combined features of guided interaction and reactive supervision to produce a hybrid approach. They provided an introduction to the hardware and once they were confident that children knew "the basics" they were able to identify the children that needed a guided interaction approach and those for whom an approach closer to reactive supervision would suffice.

When we first got [the computers] we had a list up to show that everyone was getting a go and we could see who needed help and just taught them the basics so that all the children knew how to look after it properly, how to shut it down properly, how to turn it on, what to do... just to make sure it didn't get broken and also to see what they were all like with the computer. And so they all got a fair chance at it and from that you... got an idea of the one who you needed to sit with and encourage to play with it a lot and which ones were happy to go off and play with it themselves.

However, most settings did not have any formal procedures for introducing children to ICT. Examples of adult-child interaction at the computer were relatively rare and it was the lack of adult guidance that was noteworthy. Interview data showed that staff did not discuss strategies for adult involvement in computer play. Although practitioners felt that children would benefit from a structured introduction to computers, they had not considered how this might be achieved in learning environments that favoured free play as a vehicle for learning.

\section{Discussion: guided interaction and playing with the computer}

Our observations suggested that computer play does not always act as a support for learning. We found examples of software that informed children that their answer was incorrect without explaining why and other games that gave the correct response after repeated incorrect answers but did nothing to draw a child's attention to why this was the correct response. This is unlikely to support learning and falls short of the facilitation provided by an adult who can identify the source of the error, the tentative nature of newly acquired concepts, and the benefits of directing a child to more concrete or active forms of learning. These observations point to the need not only for a more developed pedagogy for the use of computers in the playroom but also for practitioners to have opportunities to become more familiar with the software available and to be encouraged to be more critical about whether or not the learning model inherent in software matches their own models of learning and the needs of the children for whom they are responsible.

The low level of practitioner confidence was a contributory factor, as was the practical difficulty of supervising children at the computer as well as those engaged in other activities. (Very few practitioners wanted more computers for this reason.) Although practitioners are used to making close observations of the children in their care and using these observations to chart children's development, they were unable to articu- 
late what was being learned because they did not yet have the skills to record learning with computers. There were few formal examples of practitioners observing, recording, and assessing children's progress with ICT, partly because these activities do not feature prominently in the curriculum framework and also because they have received no training on how to do this. Training opportunities were very limited and generally took place on an ad hoc basis in the workplace so the emphasis was on low-level troubleshooting and basic skills rather than pedagogy.

\section{Play and learning}

Play as a medium for learning is embedded in the training of practitioners and in the curriculum document (SCCC, 1999) that guides practice and is fundamental to the inspection of provision and government funding. Playroom staff and managers were confident that almost all children enjoyed playing with the computer. Nevertheless, they found it difficult to describe the ways in which they knew that children were learning or to give examples of learning taking place. Instead, they made generalised suggestions that computer-based activities contributed to the development of mathematics and numeracy, language and literacy, social and emotional development, fine motor skills and hand-eye coordination and to knowledge and understanding (that is to each of the five areas of the pre-school curriculum in Scotland). To some extent practitioners' expectations about learning appeared to be shaped by the marketing of the software.

Although a relationship between play and learning is well established, this relationship is under-theorised with respect to uses of computers. Wood and Bennett (1997) state that "if play provides valuable contexts for learning, it must also provide valuable opportunities for teaching" but we did not find evidence of this. Sutton-Smith (1979) points to two main ways of conceptualising play. The primary paradigm describes play as leading to cognitive and creative benefits and the secondary paradigm sees play as a form of human communication and a reflection of the enculturative processes of society. Practitioners tended to see play with computers as functioning in the secondary paradigm, particularly in terms of preparing children for the information society, but they were less able to articulate the value of play with computers in terms of cognitive development.

Interviews revealed that practitioners' beliefs in the benefits of computers rested mainly on the assumption that computer skills and familiarity with technology would be valuable for future schooling and employment and that computer play provided general exposure in a way that would be valuable. Associated with this was a less explicit belief that technological interactivity confers educational value and that supervision at the computer was not necessary because interactivity means the computer is responsive to the child. In practice, it was the technological interactivity that caused problems as children had not been introduced to interface conventions and could not read instructions. Although "free flow" play activities (Bruce, 1991) are an aspiration in pre-school education, they were not usually possible with computers because of the difficulties for novices interacting with the technology. 
Nevertheless, practitioners believed in the value of computers as a play activity. This position was informed by the almost universal belief that children intuitively know how to use computers and was reinforced by what was perceived as children's lack of fear, especially in contrast to the practitioners' lack of confidence.

\section{Scaffolding and guided interaction}

Unsurprisingly, the settings where there was a practitioner who felt confident and competent with ICT seemed to have a more coordinated approach to the level of supervision and guidance required by children. They favoured some explicit tuition, were more aware of specific ways in which children could benefit from ICT, and had some understanding of the role of the practitioner in facilitating this learning.

The Zone of Proximal Development (Vygotsky, 1978) proposes that children's development requires adult guidance or collaboration with more capable peers for challenge and support. The related metaphor of scaffolding describes the means by which children's competencies can be extended by providing supporting structures (Wood, Bruner \& Ross, 1976). Guided interaction refers to supporting children's use of an artefact in a sociocognitive system which encompasses the users, their interactions, and the wider cultural context (Wertsch, 1991) within the overarching concept of scaffolding. Most practitioners are familiar with the concept of scaffolding but this study demonstrated that explicit scaffolding, whilst common practice in other curriculum areas, was noticeable by its absence in relation to children's play with computers. As guided interaction was unusual, it was relatively straightforward to identify its characteristics when it was observed. Examples of guided interaction in other contexts include showing a child how to hold a knife and fork or a pencil, how to tie shoelaces, or how to hold a book and turn the pages.

\section{Developing practice}

While practitioners believe in the benefits of computers, these are more likely to come about when staff feel able to use resources discriminately to match children's learning needs and styles and their own theories of learning. Developing pedagogy may lead to demands for changes in practice. For example, a move to guided interaction as the most common form of support for children engaging in computer activities would require more staff time than the current reliance on reactive supervision. Our interviews with practitioners also revealed a range of issues beyond pedagogical considerations that limit the use of computers in the playroom. There were requests for more (and better tailored) training, help with identifying appropriate software, technical support, and budgets that supported the costs of consumables.

Our findings are reinforced by other sources. At the same time as we were collecting data in the case study settings Siraj-Blatchford, Sylva, Muttock, Gilden, and Bell (2002) were conducting a large scale study of effective pedagogy across the curriculum for the early years. They also found that computers were being used in a limited way and that staff rarely engaged in the type of interactions with children that we have categorised as guided interaction. In addition, a consultation exercise was conducted by Learning 
and Teaching Scotland as an additional means of informing the development of a national strategy. Responses to the survey came from a wide range of perspectives including directors of education, early years managers and advisors, and those responsible for training practitioners. The need for training or professional development dominated the responses (Stephen \& Plowman, 2003c).

Respondents also called for an active debate on the ways in which ICT can work with the existing playroom pedagogy: for the debate to be part of the professional discourse of pre-school settings (rather than confined to training courses), for critical evaluation of its use in practice, and for the debate about the desirability or otherwise of young children using ICT to be familiar to practitioners and recognised explicitly in the plans that are made for provision. Respondents wanted practitioners to be able to use their professional knowledge of child development and the ways in which children learn to inform their evaluation of the uses of ICT and its role in playroom practice. There is considerable convergence of findings from our small-scale but detailed study that explores some of the complexities of playroom practice with the less refined but widerscale survey of the consultation exercise.

The new policy framework for ICT in the early years has now been published, informed by the literature review and observational study reported here as well as findings from the consultation (Learning and Teaching Scotland, 2003). This paper has reported on the use of computers in pre-school settings and one of our main recommendations was that the focus on computers we found was too narrow. If ICT were to be defined more broadly, then some of the problems outlined here would not be as significant, although it is widely acknowledged that there is a place for computers within pre-school settings. A programme of training and support funded by the Scottish Executive and planned and managed by local authorities, along with centrally produced guidance materials and a process of monitoring and evaluating the process, is in progress.

\section{Acknowledgements}

We would like to thank the staff and children who welcomed us on our visits to the preschool settings. We have benefited from the interest and enthusiasm shown by all participants and by support from Liz Paterson at Learning and Teaching Scotland.

A development of this research (Interplay: Play, Learning \& ICT In Pre-School Education) has been funded by the UK Economic and Social Research Council's Teaching and Learning Research Programme. The project focuses on identifying ways of enhancing young children's experiences with ICT in conjunction with practitioners. More information is available at http://www.ioe.stir.ac.uk/Interplay/index.htm.

\section{References}

Brooker, L. \& Siraj-Blatchford, J. (2002). “Click on miaow!”: how children of three and four years experience the nursery computer. Contemporary Issues in Early Childhood 3, 251-273.

Bruce, T. (1991). Time to play in early childhood education. Sevenoaks: Hodder \& Stoughton. Cordes, C. \& Miller, E. (Eds) (2000). Fool's gold: a critical look at computers in childhood. College Park, MD: Alliance for Childhood. 
Healy, J. (1998). Failure to connect: how computers affect our children's minds. New York: Simon \& Schuster.

Learning and Teaching Scotland (2003). Early learning, forward thinking: the policy framework for ICT in early years. Dundee: Learning and Teaching Scotland.

Li, X. \& Atkins, M. (2004). Early childhood computer experience and cognitive and motor development. Pediatrics 113, 1715-1722.

Plowman, L. (1996a). Designing interactive media for schools: a review based on contextual observation. Information Design Journal 8, 258-266.

Plowman, L. (1996b). Narrative, linearity and interactivity: making sense of interactive multimedia. British Journal of Educational Technology 27, 92-105.

Plowman, L. \& Stephen, C. (2003). A "benign addition"? Research on ICT and pre-school children. Journal of Computer Assisted Learning 19, 149-164.

SCCC (1999). A Curriculum Framework for Children 3 to 5. Dundee: Scottish Consultative Council on the Curriculum.

Scottish Executive (2003). Pre-school places rises six per cent. News release SEed251/2003, 29.7.2003. Edinburgh: Scottish Executive.

Sharp, C. (2002). School Starting Age: European Policy and Recent Research. Paper presented at the LGA Seminar "When Should Our Children Start School?" London, November 2002. Slough: NFER.

Siraj-Blatchford, I. \& Siraj-Blatchford, J. (2003). More than computers: information and communication technology in the early years. London: British Association for Early Childhood.

Siraj-Blatchford, J. \& Siraj-Blatchford, I. (2001). IBM KidSmart early learning programme, UK evaluation report-Phase 1, 2000-2001. London: IBM.

Siraj-Blatchford, I., Sylva, K., Muttock, S., Gilden, R. \& Bell, D. (2002). Researching Effective Pedagogy in the Early Years. DfES research report 356. London: DfES.

Stephen, C. \& Plowman, L. (2003a). Information and communication technologies in pre-school settings: a review of the literature. International Journal of Early Years Education 11, 223-234.

Stephen, C. \& Plowman, L. (2003b). "Come back in two years!" A study of the use of ICT in pre-school settings. Dundee: Learning \& Teaching Scotland.

Stephen, C. \& Plowman, L. (2003c). Connecting the evidence: ICT in pre-school, unpublished report for Learning \& Teaching Scotland, Dundee.

Sutton-Smith, B. (Ed.) (1979). Play and learning. New York: John Wiley.

Vygotsky, L. (1978). Mind in society: the development of higher psychological processes. Cambridge, MA: Harvard University Press.

Wertsch, J. V. (1991). Voices of the mind: a sociocultural approach to mediated action. London: Harvester.

Wood, D., Bruner, J. \& Ross, G. (1976). The role of tutoring in problem solving. Journal of Child Psychology and Psychiatry 17, 89-100.

Wood, E. \& Bennett, N. (1997). The rhetoric and reality of play. Early Years 17, 22-27. 